\begin{tabular}{lc} 
Open Access & IRJEI, Vol: Vol: 2, Issue: 2 \\
International Research Journal of Education and Innovation & July to September 2021 \\
ISSN (ONLINE): $2710-043$ & DOI: $10.53575 /$ irjei.5-v2.2(21)30-40 \\
ISSN (PRINT): $2710-0448$ & $\underline{\text { http://www.irjei.com }}$ \\
\hline
\end{tabular}

\title{
Dynamic Role of Knowledge Management in Pakistani Universities for Competitive Advantages
}

Dr. Rehmat Shah*
Dr. Maksal Minaz
Dr. Zarina Akhtar**

\begin{abstract}
Knowledge management is a relatively new branch of management sciences discussed by different researchers and experts. It offers opportunity for both organizational and individual advancement. The objectives of this paper were; to determine knowledge management principle use as a tool for competitive advantages in university of Pakistan, to find out what the approved supervisor thinks about era of knowledge management practices in Pakistani universities. In this descriptive study the population $4636 \mathrm{PhD}$ faculty members from universities of Pakistan. Following multi-stage sampling techniques $465 \mathrm{PhD}$ faculty members constituted the sample group. Data were collected through adapted Standardized Research Questionnaire. The collected data were analyzed through Descriptive analysis (Percentage) method was used to analyzed the data. The findings of this research reveal that in Pakistani universities, there is a dearth of understanding on how to use the knowledge management principle to obtain a competitive advantage. Respondents were aware of the benefits of knowledge management principles in higher education. Furthermore, knowledge management has never been widely used in Pakistani educational institutions as a means of gaining a competitive advantage. It was recommended that Ministry of Federal Education and Training, and universities of Pakistan have to design and integrate strategic plan for use of knowledge management principles for competitive advantages.
\end{abstract}

Keywords: Knowledge Management; Competitive Advantages; Principles, Pakistani Universities

\section{Introduction}

Knowledge is now widely recognized as a crucial competitive advantage, and interest in knowledge management has risen across the board (Ajmal et al., 2010). Knowledge is primarily social, cultural, and organizational knowledge that develops over time as a result of changes in organizational activities and practices (Kock \& Queen, 1998 Davenport \& Grover, 2001). Knowledge is classified in a variety of ways by different authors and most common categories of knowledge are tacit and explicit knowledge, which include technical and strategic information (Nonaka, 1994). Individual or group knowledge can be classified as tacit and explicit knowledge are the most prevalent types of knowledge, whether practical or theoretical. (Pathirage et al., 2007, Nonaka, 1994).

Knowledge refers to familiarity, consciousness, or command, such as facts abilities, mindset, and competence of people which comes from experience. or things. The Sharing knowledge has the purpose of making it visible, demonstrating the value of knowledge in the workplace, and motivating employees to participate in activities such as knowledge sharing and

\footnotetext{
${ }^{*}$ Assistant Professor of Education, Virtual University of Pakistan.

Email: rehmatshah786@gmail.com

${ }^{* *}$ Lecturer, Department of Education, Abdul Wali Khan University Mardan.

Email: maksalminaz@awkum.edu.pk

${ }^{* * *}$ Assistant Professor of Education, International Islamic University Islamabad, Pakistan.

Email: zarina.akhtar@iiu.edu.pk
} 
infrastructure building. (Merlo, 2016).

Between 1990 and 1995, knowledge management research took off, with definitions, potential commercial benefits, and the creation of definite knowledge management projects (Nonaka, 1994; Wiig, 1994). It can also describe as a method of obtaining, organizing, and distributing information., Employee knowledge, both implicit and explicit, is shared. for use in their employment (Alavi et al., 2005, Schultze \& Leidner, 2002). Tsui (2005) claims that knowledge management is becoming more process-centric, with necessary technology gradually aligning to support process-based knowledge management operations. According to studies, every organization should use the six basic knowledge management practices

i. an emphasis on knowledge generation and transfer with protection

ii. commitment to continuous learning organizations

iii. formation of an innovative culture for creation of knowledge

iv. competency

v. strategy for people development

vi. global perspectives.

Wilson \& Campbell (2016) confirmed their classification of knowledge management into four components: knowledge generation, retrieval, sharing, and application. Knowledge management was described by Alrawi (2008) as having three points of view: informational, technological, and culturally based. Knowledge management focuses on results, processes, technology, culture, and people. There are four main motivating factors: leadership, culture, technology, and measurement (Ho, 2009). Knowledge management capability refers to the knowledge management process of developing and using knowledge within the company (Gold et al., 2001), including acquiring, converting, using, and protecting knowledge. As a result, most firms must become aware of critical aspects that can affect the success of a KM program.

In today's competitive marketplaces, competitive advantage is increasingly being viewed as one of the most important drivers of long-term success. In compared to other competitors, Lismen et al. (2004) defined competitive advantage as from the client's standpoint, there is an abundance of attractiveness in a business's proposal. A firm, as well as a higher education institution, must be competitive in order to gain a large market share and earnings. It is a company's diversity of features or dimensions that helps it to outperform its competitors in terms of customer service. The resource-based strategy also encourages the use of knowledge management to gain a competitive advantage (Alipour et al., 2010). Chuang (2004) defined knowledge management as capability of the organization and investigated the relationship between knowledge management capabilities and competitive advantage. The findings supported the influence of social knowledge management on competitive advantage. Furthermore, technical KM resource was found to be inversely related to competitive advantage, while KM capability was found to be significantly related to competitive advantage. Marques and Simón (2006) highlighted how companies who implemented KM strategies outperformed their competition. Knowledge distribution is crucial to any organization's success since it allows members to share their knowledge (Al-Alawi et al., 2007). According to the research, intangible assets include things like knowledge management, market orientation, and organizational learning.

According to Enz (2008), allow an organization to acquire those qualities that increase 
competitive advantage and lead to superior market performance. The overall impact of knowledge management systems has been to distinguish items from low-cost equivalents in the marketplace and to enable the company to fulfil its goals a long-term competitive advantage for the organizations. Knowledge management is the ability to make sense of and use data streaming into a company to gain a competitive advantage. It boosts productivity, encourages innovation, and generates a competitive edge that lasts.

In their research, Wastyn and Czarnitzki (2010) found that knowledge management approaches improve a company's innovative performance. Knowledge management, according to Bosilj and Jurinjak (2009), reduced the risk of losing a competitive advantage as a result of personnel leaving the organization. Organizational culture focuses on a company's distinguishing traits, such as how people are assigned meaning. This is a firmly ingrained culture with a slow rate of change. The behavior of employees is influenced by an organization's culture (Tierney 2008). Knowledge management techniques contribute in the enhancement of decision-making and production processes, as well as the identification of true contributors and the capture of their knowledge. As a result, the expenses of staff resignations, retirements, and transfers are decreased, knowledge loss is avoided, and employee retention is improved.

According to Taleghani et al. (2014) looked at the indirect link between knowledge management and competitive advantage gained through innovation. Today's educational institutions are susceptible to business pressures. Significant changes in competition, according to Brown and Duguid, (2000), have caused universities to think like businesses and internationalize their courses.

The phrase "communities of practice" was coined by Lave and Wenger (1991). Communities of practice (CoP) are informal organized groups of people who have a shared interest in something. A group of experts in their fields who are informally linked to one another for a common set of problems and a common for answers (Kimble, Hildreth, \& Wright, 2001). In other word the ability to produce enough excitement, relevance, and value to attract and engage members is what makes communities of practice successful over time (Wenger et al. 2002). There are various categories of learner knowledge i.e., tacit, innovative construct, school knowledge, and CoP activities that are successful can have a long-term impact on faculties of higher education institutions. Individual activity systems toward a goal and action toward a specified objective and operation are encouraged by Communities of practice. Individual members gain knowledge through taking part in a group activity. Informal learning manifests itself in the form of communities of practice.

They usually develop organically in response to common interests and issues. They tend to exist outside of official educational institutions by their very nature. Participants are frequently not searching for formal qualifications, but rather to address personal concerns and improve their skills. Furthermore, communities of practice are not limited to a single medium; individuals can meet in person for social or professional reasons or participate in online or virtual communities of practice. In the digital era, communities of practice are likely to grow more significant rather than less so; yet, thinking of them as a replacement for traditional forms of education is probably a mistake. There is no one-size-fits-all strategy to teaching design. The needs of various groups always differ in nature. Professional learning can be enhanced through the use of communities of practice. The importance of communities 
of practices in accelerating professional growth within the organization is critical. A community of practices as focuses its attention on working practices. It creates a learning culture that helps build a community where learning is supported and stimulated (Kwakman, 2003). They can express their desires and aspirations to peers who have had similar skills (Burbank \& Kauchak, 2003). With the advent of online technology, communities of practice have seen significant alterations. Keeping in view the above discussion on knowledge management this study was designed to investigate the dynamics of knowledge management in Pakistani universities.

\section{Statement of the problem}

Knowledge management (KM) is a method for assisting businesses in locating, selecting, organizing, disseminating, and transferring critical knowledge and skills required for activities such as problem solving, dynamic learning, strategic planning, and decision making. The greatest knowledge management systems will allow you to collaborate with coworkers and managers to learn new things and put what you've learned to good use. The statement of problem of this research study was what is the dynamic role of knowledge management in Pakistani universities for competitive advantages.

\section{Objectives of The Study}

Following objectives were formulated after identified the research problem:

i. To determine knowledge management principles,

ii. To investigate the use as a tool for competitive advantages in university of Pakistan.

iii. To find out faculty perceptions regarding era of knowledge management practices in universities of Pakistan.

\section{Research Questions}

Based on the objectives, following research questions were formulated;

i. How knowledge management practices are followed in Pakistani universities?

ii. How knowledge management is used a tool for competitive advantages in Pakistani universities?

iii. What are the perceptions of universities faculty members about knowledge management in Pakistani universities?

\section{Research Methodology}

The nature of this study was quantitative. The survey method was use for data collection. Efforts were made to collect quantitative data through a questionnaire about the selected research topic.

The total number of $\mathrm{PhD}$ approved supervisors was 4634. These supervisors are active participants in the supervision of PhD and MS level students. The population of this paper was all PhD faculty having status of Higher Education Commission approved supervisors. Multi-stage sampling techniques provide the opportunity to researcher to select appropriate sample. Through this technique researcher select $10 \%$ of the population of the study. In first stage, 12 different disciplines were identified through random sampling. in second stage, after selecting the strata's through proportionate random sampling technique $10 \%$ (465) 
from each stratum were selected.

The questionnaire was adapted for this study after it was used in a PhD study in the United Kingdom (Cranfield, 2011). The adapted questionnaire contented the requirement of objectives of the research study.

The questionnaire was pilot tested to ensure its reliability and validity. The overall reliability coefficient of the questionnaire was .94 which was acceptable for data collected from the sample group. Furthermore, expert opinion from $\mathrm{PhD}$ faculty was used to determine the instrument's content validity, the suggested changes in the questionnaire were properly incorporated.

By e-mail, google form, and personal visits to Pakistan's target universities, 465 questionnaires were delivered to $\mathrm{PhD}$ approved supervisors. A total of 326 questionnaires were returned from the study's sample.

Statistical Package for Social Sciences (SPSS) version 17 was used to analysis the data. To do so, a simple percentage was employed. As a data analysis technique, performed descriptive analysis was employed.

Data Analysis and interpretations

Table 1 In Pakistani universities, dialogue is encouraged and supported

\begin{tabular}{llll} 
Option & Frequency & Percent & Cumulative Percent \\
\hline It was in use prior to 1999 & 46 & 14 & 14 \\
Yes & 182 & 56 & 70 \\
No & 44 & 11 & 81 \\
Do not know & 65 & 19 & 100.0 \\
\hline
\end{tabular}

The above table reveals the perceptions of HEC approved supervisors about facilitation and the encouragement that promote dialogue in universities of Pakistan. The table have four categories which describe the opinion of faculty members. The primary category (in use before 1999) is $14 \%$ of the respondents. The $2^{\text {nd }}$ category of the table shows that they facilitate and encourage dialogue in universities of Pakistan with response rate of $56 \%$ of the respondent. In the third category of the table, just $11 \%$ of respondents were unfavourable about encouraging and facilitating discourse in Pakistani colleges. There are $19 \%$ of respondents that do not recognize the importance of encouraging and facilitating dialogue in their particular universities. 
Table 2 In Pakistani universities, communities of practice are encouraged

\begin{tabular}{llll} 
Option & Frequency & Percent & Cumulative Percent \\
\hline It was in use prior to 1999 & 41 & 13 & 13 \\
Yes & 176 & 54 & 67 \\
No & 44 & 13 & 80 \\
Do not know & 65 & 19 & 100.0
\end{tabular}

The above-mentioned table recognised situation about communities of practice is encouraged in Pakistani colleges. The table's four categories depicted how respondents felt about the institution's support for communities of practice. The first question category, which was used previous to 1999, is only regarded as 13\%. The institution in Pakistan's universities encourages verifiable communities of practice, according to a 54 percent positive reaction. The institution only encourages 14 percent of the negative responses about communities of practice. There were $22 \%$ of respondents who did not know about communities of practice and were urged to join them at their individual universities.

Table 3 Staff knowledge or information is frequently updated in databases of good work practices and lessons learned

\begin{tabular}{llll} 
Option & Frequency & Percent & Cumulative Percent \\
\hline It was in use prior to 1999 & 31 & 10 & 10 \\
Yes & 171 & 52 & 62 \\
No & 54 & 17 & 79 \\
I'm not sure & 70 & 21 & 100.0
\end{tabular}

The four sections of the table show respondents' awareness of staff knowledge or information on effective work practices, as well as lessons learned, which are updated on a regular basis in the database. Prior to 1999 , just $10 \%$ of $\mathrm{PhD}$ faculty at Pakistani universities responded to the first category of inquiry. The second category confirmed employee knowledge or information by constantly updating databases of staff knowledge or information. Staff knowledge or information, which might be obtained by regularly updating databases of effective work practices and lessons learned, accounted for $17 \%$ of the negative responses. According to the survey, $21 \%$ of respondents were unaware that their

$=$ International Research Journal of Education and Innovation $=[35]=$ 
universities' databases are updated on a regular basis, implying that they are unaware of staff knowledge.

Table 4 When did universities begin to see knowledge management as a useful tool?

\begin{tabular}{llll} 
Option & Frequency & Percent & Valid Percent \\
\hline It was in use prior to 1999 8 & 3 & 3 \\
From 1995 to 2000 & 11 & 3 & 6 \\
From 2000 to 2010, & 38 & 12 & 18 \\
From 2010 to 2015 & 64 & 21 & 39 \\
Never been used & 205 & 61 & 100 \\
\hline
\end{tabular}

The above table depicts supervisors' perspectives on when their individual universities began using knowledge management as a technique. For I before 1995, 1995-2000, 20002010, and 2010-2015, there were four alternatives. Only 3\% of respondents said they employed knowledge management in Pakistani universities before to 1995. 1995-2000 was the next period of knowledge management, with only $3 \%$ of respondents responding. Between 2000 and 2010, 12 percent of approved supervisors said they used knowledge management as a technique. During the current time of the global economy, from 2010 to $2015,21 \%$ of respondents said they employed knowledge management as a technique in their respective universities. 61\% respondents said they had never used knowledge management as a modern strategy for competitive advantage in Pakistani universities.

Table 5 Pakistan's universities have the right culture to apply knowledge management techniques to gain a competitive advantage
Option
Frequency Percent Cumulative Percent

\begin{tabular}{lccc}
\hline It was in use prior to 1999 & 32 & 10 & 10 \\
Since 1999, it has been in use & 52 & 16 & 26 \\
Use within the next 24 months & 33 & 10 & 36 \\
I'm not sure not applicable & 149 & 46 & 82 \\
No & 60 & 18 & 100.0 \\
\hline
\end{tabular}

$=$ International Research Journal of Education and Innovation 
Supervisors in Pakistani universities who have been approved by the Higher Education Commission believe that their schools have the right culture to implement the knowledge management principles listed above. For the pre- 1999 choice, $10 \%$ of respondents said their universities had the necessary culture to utilize knowledge management principles. The second category, which garnered 16 percent of replies from HEC certified supervisors, was (usage since 1999) their universities have the right culture to employ knowledge management principles. Institutions with the necessary culture to use Knowledge Management concepts will be planned in the near future in the next 24 months, according to $10 \%$ of respondents. Respondents said they didn't know enough about the correct culture to apply knowledge management concepts as a tool to improve universities' capabilities, with $46 \%$ saying they didn't know enough. According to $18 \%$ of approved supervisors, their universities have the culture to use knowledge management ideas as a tool.

Table 6 In Pakistani universities, knowledge management principles are being used as a management technique to gain a competitive advantage

\begin{tabular}{llll} 
Option & Frequency & Percent & Cumulative Percent \\
\hline It was in use prior to 1999 & 28 & 9 & 9 \\
Since 1999, it has been in use & 44 & 13 & 22 \\
Use within the next 24 months & 24 & 7 & 29 \\
I'm not sure/ not applicable & 155 & 47 & 76 \\
No & 75 & 24 & 100.0
\end{tabular}

The above Table defines the views of HEC approved supervisor on the principles of knowledge management in Pakistani universities as a competitive advantage management tool. Prior to $1999,9 \%$ of respondents said they employed the knowledge management principle as a management technique in Pakistani universities. Knowledge management principles have been employed as a management technique since 1999, according to the second group, which obtained $13 \%$ of replies. The third area of the inquiry was about their university's strategy for the next two years, and 47 percent of respondents said they didn't comprehend the principles of knowledge management as a management tool for higher education. According to 24 percent of HEC certified supervisors, their universities have never implemented knowledge management concepts as a competitive advantage strategy.

\section{Findings:}

Findings of the study were appended below after data analysis.

1. There was agreement on dialogue that is encouraged and facilitated inpublic and private universities of Pakistan.

$=$ International Research Journal of Education and Innovation 
2. Majority of PhDs approved supervisor know that communities of practice are encouraged and facilitated in universities of Pakistan.

3. It was also revealed that staff knowledge was frequently updated in databases of good work practices in Pakistani universities.

4. $\mathrm{PhD}$ approved supervising faculty at Pakistani universities are aware that their institutions never regard knowledge management as a tool to be utilized. PhD Approved supervisors believe that there is no proper culture in Pakistani universities for using knowledge management principles to gain a competitive advantage.

5. Knowledge management has never been used as a tool in a Pakistani institution, according to the majority of supervisors.

\section{Discussions}

The results of this paper about dialogue is encouraged and facilitated in Pakistani universities confirmed by Alavi \& Leidner, (2001) that externalization of knowledge creation tacit knowledge is transformed to explicit knowledge through the process of dialogue and collaboration. The results of this study about communities of practice are encouraged and facilitated in universities of Pakistan were supported by (Jakovljevic, Buckley, \& Bushney, (2013).

The results further clarified that communities of practice are eager for new relationships and challenges to work collegially and collaboratively for the purpose of knowledge sharing. The communities of practices were encouraged in Pakistani universities are supported by the study of Alavi and Leidner (2001), Cranfield (2011), and Ruggles (1998).

The findings of this paper also confirmed by Kezar, \& Gehrke, (2017) that they identified six main areas of communities to engage and spread reforms continuity of their growth. The findings of the study supported by the results of Ahmad\& Rafiq, (2018). That workers share new knowledge or information and work of good practices updated in databases on regularly basis.

According to Mannan, \& Taher, (2010) university's administration departments on the driving seat to use diverse knowledge management approaches as tools to overall university' management and human resources. The results supported that knowledge management principles can be used for competitive advantage. Respondents of this study perceived that there is no correct culture to utilized knowledge management for competitive advantages in universities and also supported by (Hakim \& Hassan, 2016; Cho \& Korte, 2014; Ho, 2009) that culture, incentives, structure, and leadership, that facilitate knowledge management activities.

\section{Conclusion:}

Following conclusions were based on findings and discussion of the research paper.

There was conclusion of the study that dialogue is encouraged and facilitated in universities of Pakistan.

Similarly, the Pakistani universities PhDs approved supervisors believed that communities of practice are encouraged and facilitated in universities of Pakistan.

The conclusion was that in Pakistani universities; staff expertise is regularly updated in databases of lessons learned and good work. 
It was further concluded that Pakistani universities never consider knowledge management as a tool for improvement

There was conclusion no that no correct culture is available in universities of Pakistan to utilize knowledge management principles.

\section{Recommendation:}

1. There is need of implementation plan to consider knowledge management as a tool for development and competitive advantages.

2. Universities of Pakistan are required to create correct culture for knowledge management practices.

\section{References}

1. Ahmad, K., \& Rafiq, M. (2018). Methods of Knowledge Management Practices in Pakistani Universities' Libraries. NUST Journal of Social Sciences and Humanities, 4(1), 115-126.

2. Ajmal, M., Helo, P., \& Kekäle, T. (2010). Critical factors for knowledge management in project business. Journal of knowledge management.

3. Alavi, M., \& Leidner, D. E. (2001). Knowledge management and knowledge management systems: Conceptual foundations and research issues. MIS quarterly, 107-136.

4. Alavi, M., Kayworth, T. R., \& Leidner, D. E. (2005). An empirical examination of the influence of organizational culture on knowledge management practices. Journal of management information systems, 22(3), 191-224.

5. Al-Hakim, L. A., \& Hassan, S. (2016). Core requirements of knowledge management implementation, innovation and organizational performance. Journal of Business Economics and Management, 17(1), 109-124.

6. Alipour, H., Davabi, K., Mehrabi, Z., \& Moshtaghi, M. (2010). The role of knowledge management in achievement of competitive advantage: A case study of Iran Alborze Insurance Company in Western Mazandaran. African Journal of Business Management, 4(7), 1346-1350.

7. Alrawi, K. W. (2008). Knowledge management and organization's perception in the United Arab Emirates: case study. International Journal of Commerce and Management.

8. Bosilj, N., \& Jurinjak, I. (2009). The role of knowledge management in mobile marketing. Journal of Information and Organizational Sciences, 33(2), 231-241.

9. Botha, J., \& Kourkoutas, E. (2016). A community of practice as an inclusive model to support children with social, emotional and behavioural difficulties in school contexts. International journal of inclusive education, 20(7), 784-799.

10. Burbank, M. D., \& Kauchak, D. (2003). An alternative model for professional development: Investigations into effective collaboration. Teaching and teacher education, 19(5), 499-514.

11. Cho, T., \& Korte, R. (2014). Managing knowledge performance: testing the components of a knowledge management system on organizational performance. Asia Pacific Education Review, 15(2), 313-327.

12. Chuang, S. H. (2004). A resource-based perspective on knowledge management capability and competitive advantage: an empirical investigation. Expert systems with applications, 27(3), 459465.

13. Cranfield, D. (2011). Knowledge management and higher education: A UK case study using grounded theory (Doctoral dissertation, University of Southampton).

14. Enz, C. A. (2008). Creating a competitive advantage by building resource capability: The case of Outback Steakhouse Korea. Cornell Hospitality Quarterly, 49(1), 73-78.

15. Gold, A. H., Malhotra, A., \& Segars, A. H. (2001). Knowledge management: An organizational 
capabilities perspective. Journal of management information systems, 18(1), 185-214.

16. Ho, C. T. (2009). The relationship between knowledge management enablers and performance. Industrial Management \& Data Systems.

17. Ho, C. T. (2009). The relationship between knowledge management enablers and performance. Industrial Management \& Data Systems.

18. Jakovljevic, M., Buckley, S., \& Bushney, M. (2013). Forming communities of practice in higher education: A theoretical perspective.

19. Kimble, C., Hildreth, P., \& Wright, P. (2001). Communities of practice: going virtual. In Knowledge management and business model innovation (pp. 216-230). IGI Global.

20. Kwakman, K. (2003). Factors affecting teachers' participation in professional learning activities. Teaching and teacher education, 19(2), 149-170.

21. Lave, J., \& Wenger, E. (1991). Situated learning: Legitimate peripheral participation. Cambridge university press.

22. Lismen C, Margaret S, Ed S (2004) In search of sustained competitive advantage: The Impact of organizational culture, competitive strategy, and human resource management.

23. Mannan, Z., \& Taher, M. A. Knowledge Management as a Tool of Human Resource Strategy in University Administration: Bangladesh Perspective.

24. Marques, D. P., \& Simón, F. J. G. (2006). The effect of knowledge management practices on firm performance. Journal of knowledge management.

25. Merlo, T. R. (2016). Factors influencing knowledge management use in technology enterprises in southern United States. Procedia Computer Science, 99, 15-35.

26. Nonaka, I. (1994). A dynamic theory of organizational knowledge creation. Organization science, $5(1), 14-37$.

27. Pathirage, C. P., Amaratunga, D. G., \& Haigh, R. P. (2007). Tacit knowledge and organisational performance: construction industry perspective. Journal of knowledge management.

28. Ruggles, R. (1998). The state of the notion: knowledge management in practice. California management review, 40(3), 80-89.

29. Salmani, D., Taleghani, G., Akbari, A., \& Salmani, A. (2014). An investigation on the effect of organizational culture on knowledge management implementation. Management Science Letters, $4(2), 303-310$.

30. Schultze, U., \& Leidner, D. E. (2002). Studying knowledge management in information systems research: discourses and theoretical assumptions. MIS quarterly, 213-242.

31. Schultze, U., \& Leidner, D. E. (2002). Studying knowledge management in information systems research: discourses and theoretical assumptions. MIS quarterly, 213-242.

32. Tierney, W. G. (2008). The impact of culture on organizational decision-making: Theory and practice in higher education. Stylus Publishing, LLC.

33. Varun Grover, T. H. D. (2001). General perspectives on knowledge management: Fostering a research agenda. Journal of management information systems, 18(1), 5-21.

34. Wastyn, A., \& Czarnitzki, D. (2010, June). Does Professional Knowledge Management improve innovation performance at the firm level. In Conference on Opening Up Innovation: Strategy, Organization and Technology at Imperial College London Business School.

35. Wiig, K. M. (1994). Knowledge Management Foundations: Thinking about Thinking-how People and Organizations Represent, Create, and Use Knowledge. Schema Press, Limited.

36. Wilson, J. P., \& Campbell, L. (2016). Developing a knowledge management policy for ISO 9001: 2015. Journal of Knowledge Management. 